\title{
AN INVESTIGATION OF GENOTYPE-ENVIRONMENT INTERACTIONS FOR RATE OF EAR EMERGENCE IN SPRING BARLEY
}

\author{
R. S. PARODA* and J. D. HAYES \\ Department of Agricultural Botany, University College of Wales and Welsh Plant Breeding Station \\ Aberystwyth
}

Received 21.iii.70

\section{Introduction}

THE application of statistical theory to inheritance studies of quantitative characters has in many cases led to a better understanding of the genetic systems involved. Statistical techniques are commonly used which enable breeders to test for epistasis and to obtain precise and unbiased estimates of the additive and dominance components of genetic variation. However, genotype-environment interactions create difficulties in interpreting results from experiments carried out in different environments and often lead to inaccurate and biased estimates of additive and non-additive components of genetic variation. It is only in recent years that methods have been developed to detect and estimate the magnitude of genotype-environment interactions (Finlay and Wilkinson, 1963; Eberhart and Russell, 1966; Bucio Alanis, 1966; Bucio Alanis and Hill, 1966; Perkins and Jinks, 1968a, $b$; Bucio Alanis et al., 1969). The development of these analytical techniques first proposed by Yates and Cochran (1938) provide excellent tools by which results from large numbers of trials in different environments can be interpreted.

Rojas and Sprague (1952) studied the interaction of general and specific combining ability with locations and years for yield in corn and found that the latter interactions were greater than corresponding estimates involving general combining ability. Contrary to the above findings, greater interactions of general combining ability with the environment than the corresponding estimates involving specific combining ability were observed by Matzinger et al. (1959) for yield in corn, Liang (1967) for yield and other characters in Sorghum and by Paroda and Joshi (1970) for yield and components of yield in wheat. It is clear from these contradictory results that further information on additive and non-additive components in respect of their interaction with the environment is required before the pattern, if any, of such interactions can be determined.

In this paper we analyse the data for ear emergence from ten parent varieties of spring barley and their $F_{1}$ hybrids which have been grown in eight different environments in order to study the genotype-environment interactions. The pattern of ear emergence of the ten parents and their $F_{1}$ hybrids was first investigated using the analytical approaches proposed by Finlay and Wilkinson (1963) in barley, Eberhart and Russell (1966) in maize and Perkins and Jinks (1968a) in Nicotiana rustica. The diallel analysis

* Present address: Division of Genetics, Indian Agricultural Research Institute, New Delhi-12, India. 
was carried out in the way described by Jinks (1954) and Hayman $(1954 a, b)$, and estimates of the components of genetic variation were used to examine the interaction of additive and non-additive components with the environment, as well as to obtain further information about the inheritance of ear emergence in barley. The character ear emergence was selected for study because it can be precisely measured and can be greatly influenced by changes in

\section{TABLE 1}

List of spring barley genotypes used as parents in diallel crossing programme

\begin{tabular}{|c|c|c|}
\hline \multirow{2}{*}{$\begin{array}{c}\text { Parent } \\
1\end{array}$} & \multicolumn{2}{|c|}{$\begin{array}{l}\text { W.P.B.S. accession number } \\
\text { and name or other designation }\end{array}$} \\
\hline & $\mathrm{Cb} 545$ & Rika \\
\hline 2 & $\mathrm{Cb} 763$ & Proctor \\
\hline 3 & Cb 799 & Line 7-2 \\
\hline 4 & $\mathrm{Cb} 804$ & Line $21-2$ \\
\hline 5 & $\mathrm{Cb} 824$ & No. 191 \\
\hline 6 & $\mathrm{Cb} 883$ & Abed 894 \\
\hline 7 & $\mathrm{Cb} 1006$ & Otis. C.I. 17557 \\
\hline 8 & Cb 1007 & C.1. 1236 \\
\hline 9 & Cb 1008 & M-12a from Bonus \\
\hline 10 & $\mathrm{Cb} 1009$ & Bonus \\
\hline
\end{tabular}

\section{Brief details}

Medium early, 2-row, moderately high yielding cultivar. From Sweden

Moderately late, 2-row, moderately high yielding cultivar. From Britain

Early, 2-row segregate from Manchuria C.1. $2330 \times$ C.1. 5037. From Dr G. A. Wiebe, U.S.A.

Late, 2-row from Manchuria C.l. $2330 \times$ Plumage C.1. 2511. From Dr G. A. Wiebe, U.S.A.

6-row genotype with prostrate growth under certain environmental conditions. Cereal cyst nematode resistant. From Prof. S. Andersen, Denmark

Medium early, short strawed, 2-row selection with moderate yield. From Dr Vestergaard, Denmark

Extremely early 2-row genotype in U.S.D.A. World Collection. From Dr D. W. Robertson, U.S.A.

Extremely late 2-row genotype in U.S.D.A. World Collection. From Dr D. W. Robertson, U.S.A.

Early induced mutant from Bonus. From Dr A. Hagberg, Svalöf

Moderately early 2-row parent of M-12a. From Sweden

photoperiod and temperature. The principles of the analysis will apply equally well to other quantitative characters such as height and yield.

This paper also discusses the practical application of the information on genotype-environment interactions for the selection of more stable and superior genotypes.

\section{Materials and methods}

The ten barley genotypes listed in table 1 were selected for study on the basis of their differences in earliness and diversity of origin. None required vernalisation before earing. They were crossed in a diallel fashion and at 
least $25 \mathrm{~F}_{1}$ hybrids per cross and their reciprocals were produced by hand pollination in the glasshouse. The only exceptions were crosses involving Cb 1007 (No. 8), which failed to set seed when used as a female.

The plants were subjected to the following eight treatments, which are referred to as environments :

\begin{tabular}{|c|c|c|}
\hline Environment & Conditions & $\begin{array}{l}\text { Mean date } \\
\text { of germinatior }\end{array}$ \\
\hline I & $\begin{array}{l}\text { Glasshouse-Gradually increasing daylength } \\
\text { and temperature }\end{array}$ & 5.3 .65 \\
\hline II & $\begin{array}{l}\text { Glasshouse-Gradually increasing daylength } \\
\text { and temperature higher than I }\end{array}$ & 29.4 .65 \\
\hline III & $\begin{array}{l}\text { Glasshouse-Gradually decreasing daylength } \\
\text { at higher temperature than I and II }\end{array}$ & 10.6 .65 \\
\hline IV & $\begin{array}{l}\text { Field-Gradually increasing daylength and } \\
\text { temperature but lower than I, II and III }\end{array}$ & 1.4 .68 \\
\hline $\mathrm{V}$ & Growth room $-20^{\circ}$ C., $20-\mathrm{hr}$. photoperiod & 21.2.66 \\
\hline VI & Growth room $-7^{\circ}$ C., 16 -hr. photoperiod* & 8.10 .65 \\
\hline VII & Growth room-20 $20^{\circ}$ C., 16 -hr. photoperiod & 21.2 .67 \\
\hline VIII & Growth room $-15^{\circ}$ C., 13-hr. photoperiod & 21.2 .67 \\
\hline
\end{tabular}

Plants were also grown at $30^{\circ} \mathrm{C} ., 16 \mathrm{hr}$., but since a high proportion of plants died under these conditions the data have not been included in the overall analysis.

Plants subjected to treatments in growth rooms and the glasshouse were developed from seeds germinated on pads and transplanted into sterilised compost in $3 \frac{1}{2}$ in. $(9 \mathrm{~cm}$.) diameter pots contained in waterproof boxes. They were maintained in a warm glasshouse until the first leaf emerged and then introduced into the growth rooms. The light intensity was estimated to be $2000 \mathrm{ft}$.-c. in each case. Two replicates of each cross-combination were planted; because of limitations on space only two plants and their reciprocals were used in each block. The boxes containing the plants were placed on trolleys which were moved within the cabinet three times every week in order to randomise the effects of any differences in light intensity and air temperature within the room.

Plants grown in the field were planted in whalehide pots in the glasshouse and transplanted when in the first leaf stage. They were spaced 6 in. $(15 \mathrm{~cm}$.) apart within rows set $2 \mathrm{ft}$. $(61 \mathrm{~cm}$.) apart. In the field, each plot contained five plants in each of the two blocks. In every experiment, two plots of parents were included in each block. The number of days to ear emergence was recorded when the tip of the uppermost spikelet had emerged beyond the auricules of the flag leaf.

\section{Results}

\section{(a) Parent performance}

The mean time taken for the ten varieties to ear in the eight different environments with the corresponding regression coefficients is given in table 2. The mean performance of each variety was also plotted against the mean of each environment (fig. 1). On average, increased daylength and increased temperature reduced the time taken to reach ear emergence. For example, an increase in the photoperiod from 16 to $20 \mathrm{hr}$. at a constant 
temperature of $20^{\circ} \mathrm{C}$. reduced the number of days required to reach ear emergence from 69.2 (Env. VII) to 57.5 (Env. V) days. Similarly, increasing the temperature from $7^{\circ} \mathrm{C}$. to $20^{\circ} \mathrm{C}$. at a constant photoperiod of $16 \mathrm{hr}$.

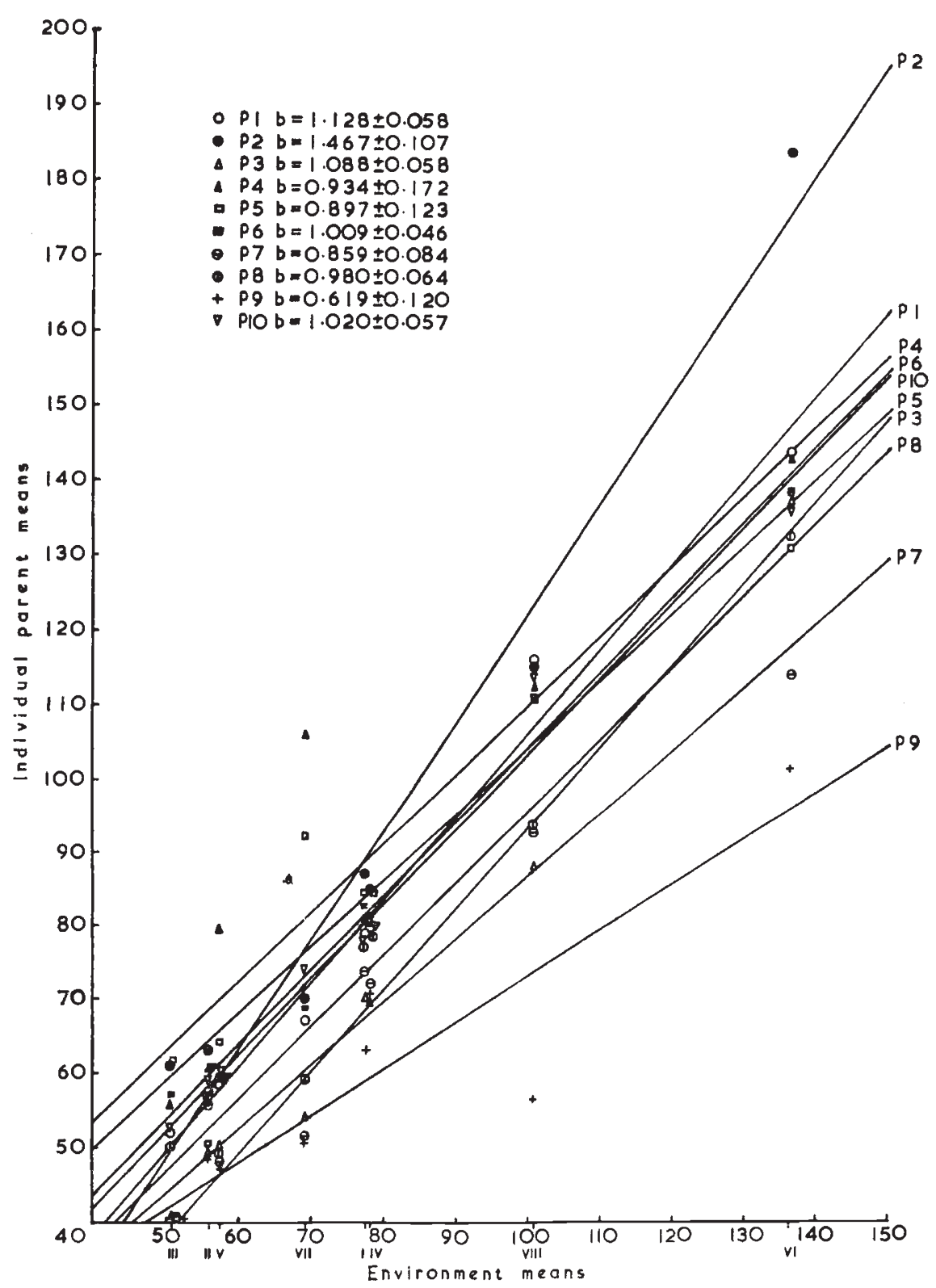

FIG. 1.-Regressions of individual parent means on environmental means.

reduced the number of days to earing from $136 \cdot 2$ (Env. VI) to $69 \cdot 2$ (Env. VII). The confounded effects of gradually changing daylength and increased temperatures are reflected in the shorter period required to ear when the 


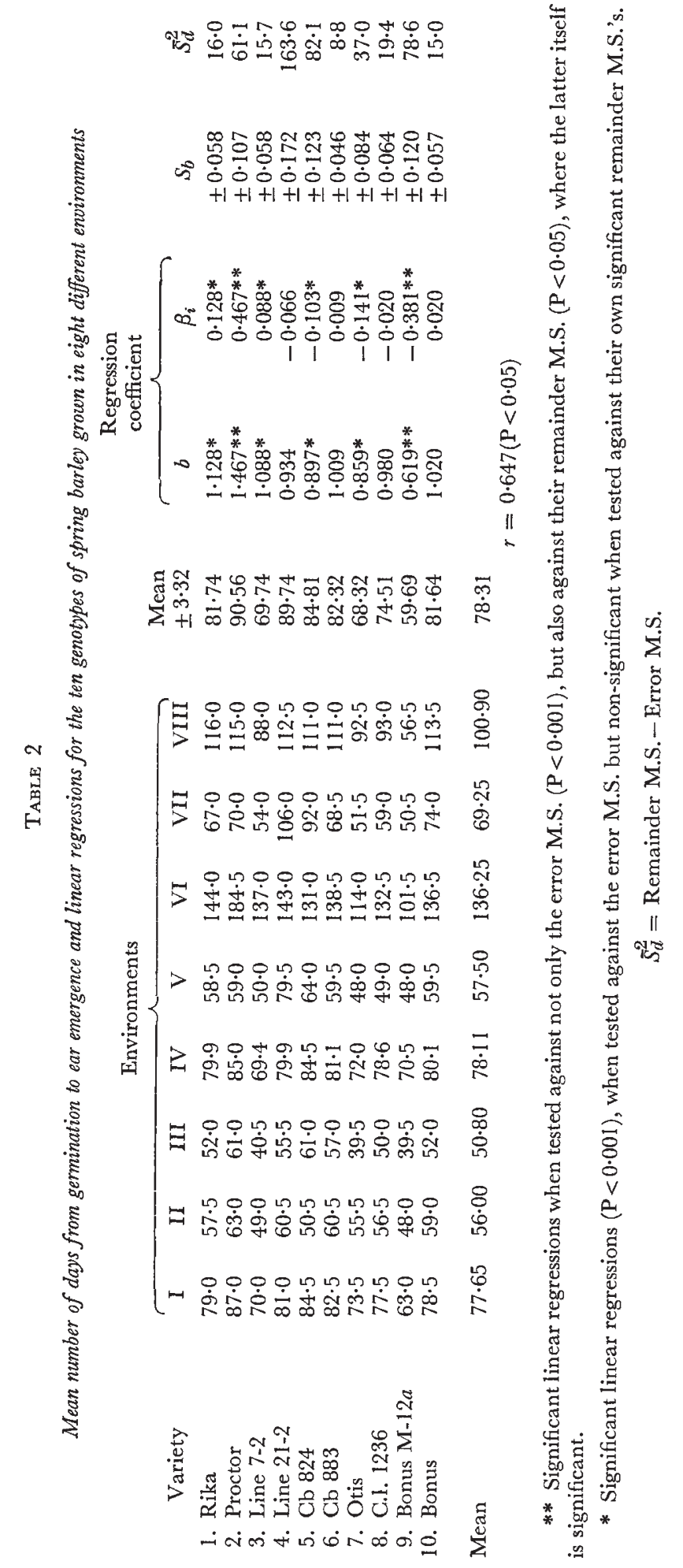


experimental material was sown at progressively later dates from March to June. Plants which germinated on 10th June and were grown in the glasshouse eared more rapidly than the plants in any other environment. In this environment (III) they were subject to a gradually decreasing period of daylength from 21 st June onwards in contrast to a gradually increasing daylength in environments I, II and IV and the constant daylength in environments V, VI, VII and VIII.

The regression coefficients $b$ in table 2 correspond to the $b$ values of Finlay and Wilkinson (1963), and to the $\left(1+\beta_{i}\right)$ values of Eberhart and Russell (1966); after subtracting 1.0 they correspond with the $\beta_{i}$ values of Perkins and Jinks (1968a). For convenience of comparison of regression values in tables 2 and 4 , the $\beta_{i}$ values are also included in table 2. Analysis

TABLE 3

Analysis of variance for ear emergence of (a) the ten parents and (b) the $45 F_{1}$ 's of barley in the eight environments

\begin{tabular}{|c|c|c|c|}
\hline \multicolumn{2}{|c|}{ (a) Parents } & \multicolumn{2}{|c|}{ (b) $\mathrm{F}_{1}$ 's } \\
\hline d.f. & M.S. & d.f. & M.S. \\
\hline 7 & $16107 \cdot 1 * *$ & 7 & $66271 \cdot 8 * *$ \\
\hline 9 & $1593.9 * *$ & 44 & $740 \cdot 2 * *$ \\
\hline 63 & $176.9 * *$ & 308 & $65 \cdot 0 * *$ \\
\hline 9 & $529 \cdot 9 * *$ & 44 & $104 \cdot 5 * *$ \\
\hline 54 & $118 \cdot 1 * *$ & 264 & $58 \cdot 4 * *$ \\
\hline 80 & $3 \cdot 42$ & 360 & $8 \cdot 18$ \\
\hline
\end{tabular}

Environments

Genotypes

Genotypes $\times$ Environments

Heterogeneity between regressions

Remainder

Error

** $\mathrm{P}<0.01$.

$8 \cdot 18$

of variance of the parent data (table $3 a$ ) showed that the mean differences between the parents and environments were highly significant. The genotype $\times$ environment interaction was also highly significant; when this interaction is partitioned, it is clear that most of the variation can be attributed to differences between the linear regression lines of the ten varieties although the remainder of the variation around the regression lines is also significant. The calculated linear regression for each variety was tested against both the error M.S. and its own remainder M.S. Six varieties showed significant regression when tested against the error M.S.; of these, two regression lines (i.e. for Proctor (No. 2) and Bonus M-12a (No. 9)) were significant when also tested against their own significant remainder M.S.

The estimates of $\bar{S}_{d}^{2}$ (calculated as remainder M.S. - error M.S.), the regression coefficients with their standard error $\left(S_{b}\right)$ and the mean of the ten varieties are also given in table 2 . The standard errors proved to be heterogeneous $\left(\chi^{2}\right.$ in the Bartlett's Test $=206.6 ; \mathrm{P}<0.001$ ), which confirms that there were distinct differences between varieties in the amount of deviation around the regression slopes and indicates that this attribute is under gene control. There was a correlation between the means and the linear regressions of the parents $(r=0.647 ; \mathrm{P}<0.05)$, with the late varieties in general being more sensitive to changes in the environment. The regression slopes of the late varieties tend to be steeper $(b>1)$ than those of the early varieties $(b<1)$. As this correlation was only significant at the 5 per cent. level, any generalisation about the sensitivity of the parents on the basis of their mean 
performance would, however, be tentative. It is also important to see whether similar association persists over the generations. This point will be considered in section $(b)$.

The irradiated mutant M-12a from Bonus (No. 9) was the earliest in all environments, a feature which becomes more pronounced in environments which delayed heading in other varieties. This is reflected in the regression value of $b=0.619$ for this genotype. It is, on average, much less responsive to changes in the environment than other varieties. However, the value of $\bar{S}_{d}^{2}$ for M-12a was high $(78 \cdot 6)$, which indicates that there was considerable variation around the regression slope. Line 7-2 (No. 3), while being nearly as early as the Bonus mutant in environments which promoted early flowering, was relatively later in those environments which delayed flowering, consequently the $b$ value was larger $(b=1 \cdot 088)$, but the deviation around the regression slope was low $\left(\bar{S}_{d}^{2}=15 \cdot 7\right)$ in comparison with the deviations of the other two early varieties: viz. Bonus M-12a (No. 9) and Otis (No. 7). In having regression values which approach unity, Cb 883 (No. 6) corresponds most closely to the average response of all the varieties in the different environments, although C.I. 1236 (No. 8) and Bonus (No. 10) were very similar in pattern of response. The two late varieties, viz. Proctor (No. 2) and Line 21-2 (No. 4), interacted very strongly with changes in the environment. Under the relatively high temperature conditions experienced in environment $\mathrm{V}\left(20^{\circ} \mathrm{C}\right.$., $20 \mathrm{hr}$.) and environment VII $\left(20^{\circ} \mathrm{C}\right.$., $16 \mathrm{hr}$.), Line 21-2 (No. 4) was very late compared with the mean for the remaining varieties and Proctor. This fact is reflected by the highest deviation $\left(\bar{S}_{d}^{2}=\right.$ 163.6) of Line $21-2$ around its regression slope $(b=0.934)$ when compared with the deviation of the other varieties. In contrast, under the low temperature conditions in environment VI ( $7^{\circ} \mathrm{C}$., $16 \mathrm{hr}$.), Line $21-2$ performed more like the average, and Proctor was very late. In the remaining environments Proctor was on average 4.5 days later earing than Line 21-2. The regression coefficient of $b=1 \cdot 467$ for Proctor indicates that it has an above average level of response to the factors in the environments which delay ear emergence.

\section{(b) $F_{1}$ hybrid performance}

The joint regression analysis for the $\mathrm{F}_{1}$ 's (table $3 b$ ) confirms that there were significant differences between the means for the different environments and the $\mathrm{F}_{1}$ hybrids. In addition, the variances due to genotype-environment interactions, heterogeneity between regressions and the remainder were all significant, confirming the presence of genotype-environment interactions in the $F_{1}$ generation. As with the parent analysis a large and significant portion of these interactions was attributable to differences between the linear function of the environmental means.

The mean values of the $F_{1}$ 's over all environments, the $\bar{S}_{d}^{2}$ (see Eberhart and Russell, 1966), $\beta_{(i l)}$ and $h_{(i l)}$ values (see Perkins and Jinks, 1968a) are given in table 4 . A comparison of the mean parent and $F_{1}$ values showed that on average there was partial dominance towards earliness.

The range of the dominance contributions $\left(h_{(i l)}\right)$ of the $\mathrm{F}_{1}$ 's $(-13.20$ to $9 \cdot 19)$ was less than the range of the additive genetic contributions $\left(d^{\prime}{ }_{i}\right.$ or the parental means) of the parents (see table 2). Also the range of the linear regression coefficients $\left(\beta_{(i l)}\right)$ of the $F_{1}$ 's $(-0.34$ to 0.16$)$ was less than the 


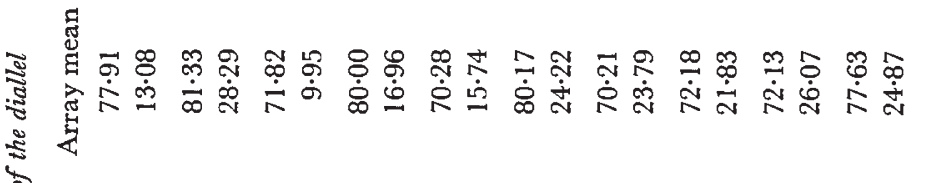

ๆ

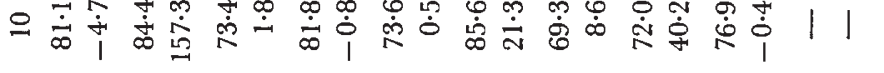

蒫苞部 .

s 类

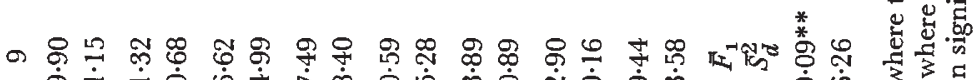

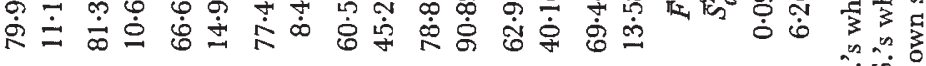

至

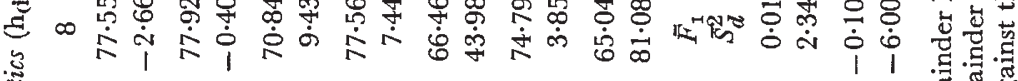

.

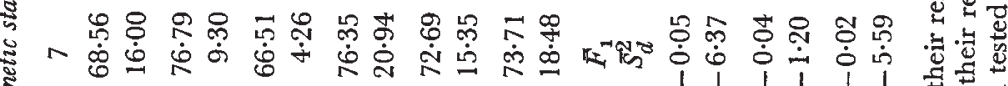

可 离

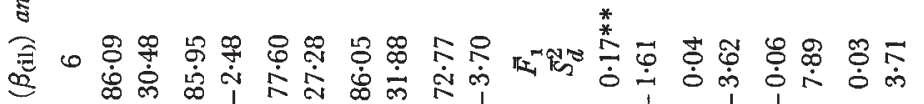

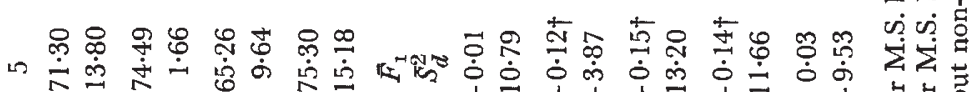
苛.

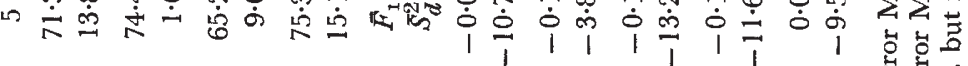

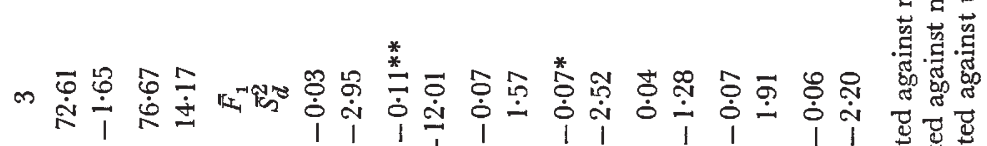

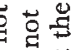

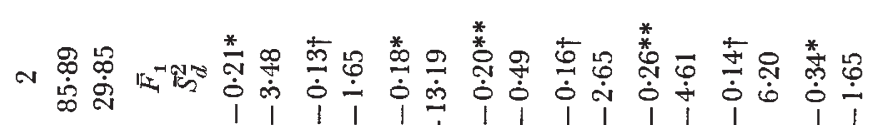
总胥芯

造语

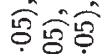

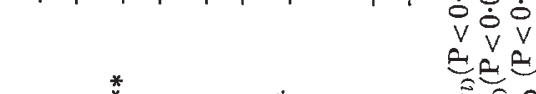

-

$\stackrel{8}{2}$

疍

पि

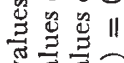

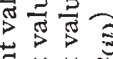

藏藏

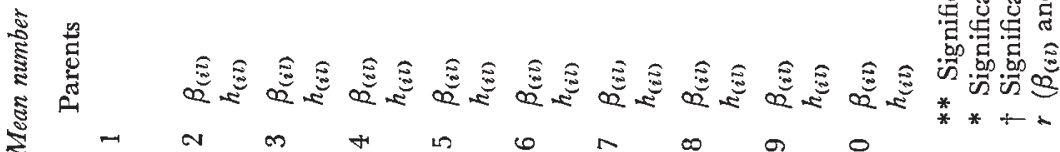


range of the linear regression coefficients of the parents. Similarly, the $\mathrm{F}_{1}$ 's exhibited less deviation around the regression slopes $\left(\bar{S}_{d}^{2}\right)$ than the parents.

The $\beta_{(i l)}$ values were significant for $23 \mathrm{~F}_{1}$ crosses, of these only 12 were significant against their remainder M.S.'s (marked as ** or * in table 4). The distribution of these significant $\beta_{(i l)}$ 's was not at random but they were concentrated in arrays $1,2,3,6$ and 10 . All the parents in these arrays had a regression coefficient greater than unity. This revealed that $F_{1}$ hybrids from crosses involving one or both parents which had regression slopes greater than one, tended to show a high linear response to environmental variation. This can be explained by the action of dominance for this character. All the $\mathbf{F}_{1}$ crosses with Proctor (No. 2) as a parent had

TABLE $5 a$

Analysis of variance of the diallel table for ear emergence in barley Individual environments

Mean squares

\begin{tabular}{|c|c|c|c|c|c|c|c|c|c|}
\hline Source & d.f. & Env. I & Env. II & Env. III & Env. IV & Env. V & Env.VI & Env. VII & Env. VIII \\
\hline Replicates & 1 & $8 \cdot 40^{*}$ & $2 \cdot 20$ & $132 \cdot 84 * *$ & 0.01 & $14 \cdot 58 *$ & $1176 \cdot 12^{* *}$ & 0.24 & $16 \cdot 24$ \\
\hline$a$ & 9 & $166 \cdot 36 * *$ & $196 \cdot 99 * *$ & $276 \cdot 06 * *$ & $221 \cdot 24 * *$ & $367 \cdot 15 * *$ & $1148 \cdot 15 * *$ & $1189 \cdot 56 * *$ & $1272 \cdot 20 * *$ \\
\hline$b$ & 45 & $12 \cdot 69 * *$ & $11 \cdot 55^{* *}$ & $45 \cdot 01 * *$ & $8 \cdot 23 * *$ & $17 \cdot 74 * *$ & $82 \cdot 37 * *$ & $169 \cdot 66 * *$ & $167 \cdot 86 * *$ \\
\hline$b_{1}$ & 1 & $7 \cdot 56 *$ & $13 \cdot 08 * *$ & $19 \cdot 21 * *$ & $52 \cdot 90^{* *} *$ & $98 \cdot 01 * *$ & $468 \cdot 72 * *$ & $262 \cdot 98 * *$ & $13 \cdot 56$ \\
\hline$b_{2}$ & 9 & $43 \cdot 16 * *$ & $13 \cdot 73 * *$ & $46 \cdot 34 * *$ & $30 \cdot 47 * *$ & $36 \cdot 86 * *$ & $172 \cdot 63 * *$ & $294 \cdot 08 * *$ & $212 \cdot 21 * *$ \\
\hline$b_{3}$ & 35 & $4 \cdot 99 * *$ & $10 \cdot 94 * *$ & $45 \cdot 46 * *$ & $1 \cdot 23$ & $10 \cdot 52 *$ & $48 \cdot 12$ & $134.99 * *$ & $160 \cdot 86 * *$ \\
\hline$c$ & 9 & $1 \cdot 73$ & $2 \cdot 09$ & 1.79 & $2 \cdot 36$ & $4 \cdot 21$ & $39 \cdot 42$ & $6 \cdot 37$ & $7 \cdot 81$ \\
\hline$d$ & 36 & $1 \cdot 41$ & $1 \cdot 65$ & $2 \cdot 17$ & $1 \cdot 74$ & $4 \cdot 59$ & $36 \cdot 75$ & $3 \cdot 12$ & $12 \cdot 35$ \\
\hline Error & 99 & $1 \cdot 91$ & $2 \cdot 24$ & $5 \cdot 57$ & $0 \cdot 87$ & $3 \cdot 55$ & $49 \cdot 13$ & $10 \cdot 49$ & $14 \cdot 01$ \\
\hline
\end{tabular}

significant $\beta_{(i l)}$ values. However, predictions cannot be made for the genotype-environment interactions as most of these $F_{1}$ 's displayed a wide range of deviations from their regression lines. Considerable variation was noted in the values of the deviations around the regression slopes $\left(\bar{S}_{d}^{2}\right)$ for $\mathrm{F}_{1}$ 's in the different arrays. $F_{1}$ 's in array 3 (involving Line 7-2) showed least deviations around their regression slopes but only four $\beta_{(i l)}$ values were significant. Thus, different parents showed dominance for both the regression slope and the deviations around the slope confirming that both attributes are under the control of different gene systems. Thus, the individual means, the regression slope and the deviation around the slope must all be considered in evaluating the potential performance of genotypes.

The correlation between $\beta_{(i l)}$ and $h_{(i l)}$ values was poor $(r=0.224)$. Thus in contrast to the parents, the mean rate of ear emergence of the $F_{1}$ 's was not significantly correlated with their regression slopes.

\section{(c) Diallel analysis and interpretations of the $\mathrm{Wr} / \mathrm{Vr}$ graphs}

The $F_{1}$ and parental data were analysed using the graphical and statistical techniques developed by Jinks and Hayman (1953), Hayman (1954a, $b$ ) and Jinks (1954). Analysis of variance of the diallel tables (table 5a) indicated the presence of significant additive and dominance components and the absence of reciprocal differences in all the environments. The error variances were relatively high in the controlled environments reflecting the 
inherent variation in growth rooms and the lower level of replication of plants per plot.

In the analysis over all environments (table $5 b$ ) the genetical variation amongst the parents $a$ was significant and accounted for a high proportion of the total variation. The overall dominance component $b$ was smaller but significant. The significant $b_{1}$ value confirms that the $\mathrm{F}_{1}$ hybrids exhibited dominance for earliness. The $F_{1}$ hybrids took on average $75 \cdot 4$ days after germination to reach ear emergence compared with $78 \cdot 3$ days for the parents. There is strong evidence of asymmetry at loci showing dominance for earliness $\left(b_{2}\right)$. Although there is some evidence of maternal

TABLE $5 b$

Pooled analysis over eight environments

$\begin{array}{crccc}\text { Source } & \text { d.f. } & \text { Mean squares } & \begin{array}{c}\text { V.R. } \\ \text { (pooled } \\ \text { error) }\end{array} & \begin{array}{c}\text { V.R. } \\ \text { (component } \\ \text { interaction) }\end{array} \\ a & 9 & 3568 \cdot 5 & 327 \cdot 4^{* *} & 19 \cdot 7 * * \\ b & 45 & 179 \cdot 4 & 5 \cdot 5^{* *} & 3 \cdot 7 * * \\ b_{1} & 1 & 603 \cdot 3 & 34 \cdot 9^{* *} & 12 \cdot 7 * * \\ b_{2} & 9 & 380 \cdot 9 & 10 \cdot 6^{* *} & 5 \cdot 7 * * \\ b_{3} & 35 & 115 \cdot 5 & 1 \cdot 41 & 2 \cdot 6 * * \\ c & 9 & 15 \cdot 7 & 0 \cdot 83 & 2 \cdot 2 * \\ d & 36 & 9 \cdot 0 & & 1 \cdot 2 \\ \text { Environment } & 7 & 82291 \cdot 8 & 7549 \cdot 70^{* *} & - \\ a \times \mathrm{E} & 63 & 181 \cdot 3 & 16 \cdot 6^{* *} & - \\ b \times \mathrm{E} & 315 & 47 \cdot 9 & 4 \cdot 4^{* *} & - \\ b_{1} \times \mathrm{E} & 7 & 47 \cdot 5 & 4 \cdot 4^{* *} & - \\ b_{2} \times \mathrm{E} & 63 & 66 \cdot 9 & 6 \cdot 1^{* *} & - \\ b_{3} \times \mathrm{E} & 245 & 45 \cdot 1 & 4 \cdot 1^{* *} & - \\ c \times \mathrm{E} & 63 & 7 \cdot 1 & 0 \cdot 65 & - \\ d \times \mathrm{E} & 252 & 7 \cdot 8 & 0 \cdot 72 & - \\ \text { Pooled error } & 792 & 10 \cdot 9 & - & \end{array}$

effect $c$, when tested against its own environmental interaction mean variance, it is not significant when tested against the pooled error. As observed in table $3(a)$ and $(b)$, the differences between the environments were significant, but in addition the results of these analyses show that the additive and each of the dominance components interacted strongly with the environments.

The $W r / V r$ graphs for the eight different environments are given in fig. 2 which also includes the graph for the pooled data from all environments. The graphs provide information on mean dominance, relative dominance of the parents and evidence of epistasis, when present. Since one of the basic assumptions in the diallel cross analysis is that epistasis is not operating, it was considered essential to establish the presence or absence of epistasis in each environment. A deviation of the regression slope from unity $(b=1)$ in the diallel graph generally indicates the presence of epistasis, although other causes such as correlated gene distributions cannot be excluded, the significance of differences in $b$ in each environment was tested by using the $t$ value of $(1-b) / S_{b}$ with $n-2$ degrees of freedom. Except for environment III and VII, all other environments had regression coefficients 
which were not significantly different from unity. In environments III and VII the regression lines $(b=-0.07 \pm 0.215$ and $b=0.40 \pm 0.340$, respectively) deviated significantly from unity but not from zero. Various arrays were then eliminated from the diallel tables as suggested by Hayman $(1954 b)$. In environment III the elimination of array 6 (involving parent
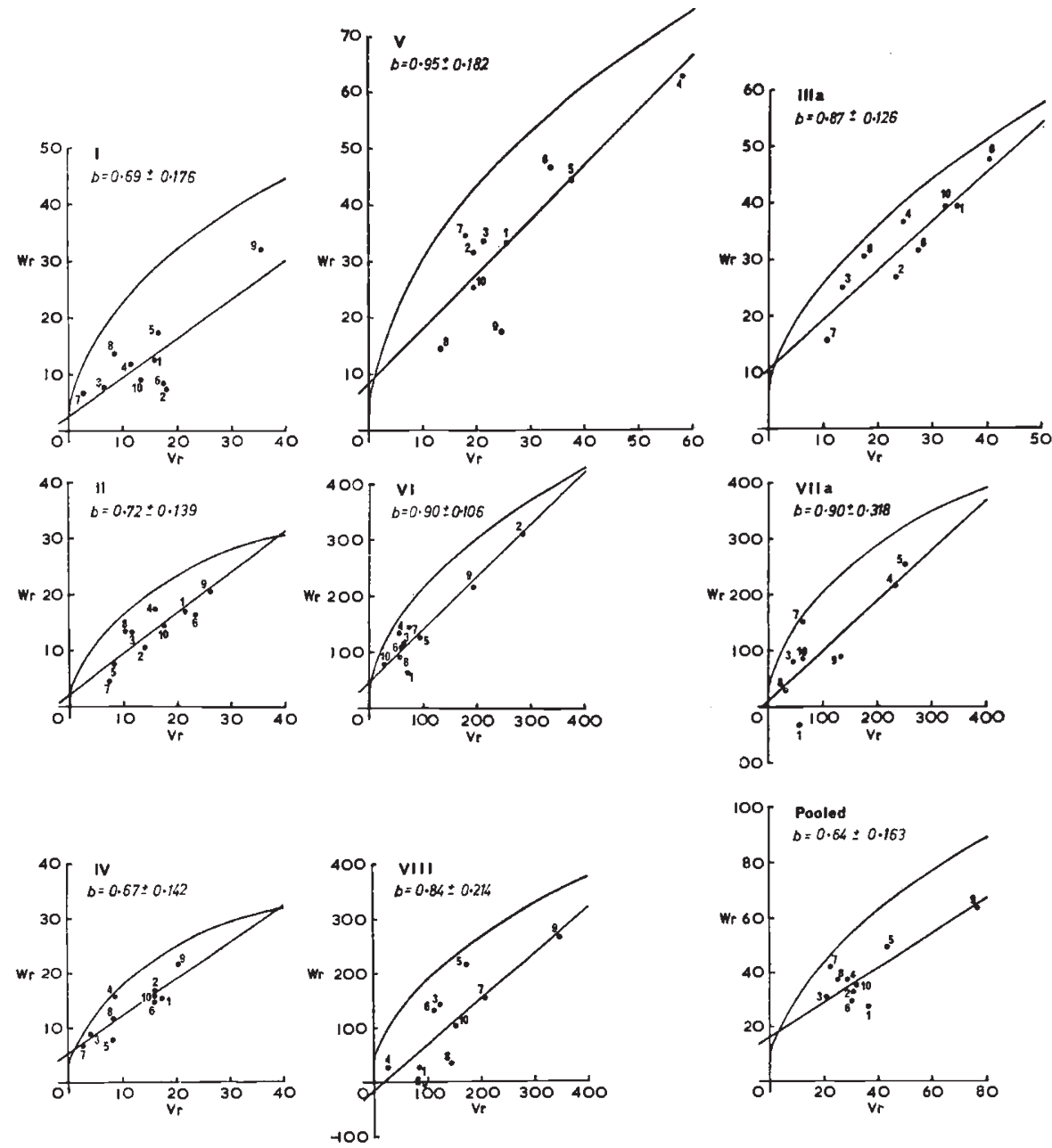

FIG. 2.- The $W r / V r$ graphs for the eight environments and pooled data.

$\mathrm{Cb} 824)$ improved the slope of the line so that $b$ was not significantly different from unity. In environment VII, the elimination of single arrays did not significantly change the slope, so pairs of arrays were eliminated. Elimination of array 2 (involving Proctor) and 6 (involving $\mathrm{Cb} 883$ ) resulted in a regression coefficient which did not differ significantly from unity. The elimination of different arrays in these two environments indicated that epistasis might be operating and that it was not due to the same parent in each case. The $W r / V r$ graphs for environments III and VII, after removing the interacting arrays, were drawn and are shown in fig. 2 as III $a$ and VII $a$ respectively. 
The regression lines cut the ordinates just above the point of origin in most cases and thus indicate partial dominance. However, in environment VIII the regression line cuts the ordinate just below the origin, although since the lines have not been corrected for experimental error this apparent overdominance may be a case of full dominance. In most cases (I, II, III $a$ IV and VIII) the early mutant (No. 9), by taking a position on the regression slope furthest away from the origin, indicates that earliness in this genotype was recessive. In the remaining cases varieties $6,2,4$ and 5 occupied the

TABLE 6

Estimates of the components of genetic variation for date of ear emergence in the eight environments Environments

\begin{tabular}{|c|c|c|c|c|c|c|c|c|}
\hline Components & I & II & III & IV & V & VI & VII & VIII \\
\hline$D$ & $\begin{array}{r}49 \cdot 43 \\
\pm 4 \cdot 06\end{array}$ & $\begin{array}{r}24.92 \\
\pm 2 \cdot 41\end{array}$ & $\begin{array}{r}59 \cdot 18 \\
\pm 2 \cdot 64\end{array}$ & $\begin{array}{r}30 \cdot 12 \\
\pm 2 \cdot 13\end{array}$ & $\begin{array}{r}90 \cdot 50 \\
\pm 5 \cdot 03\end{array}$ & $\begin{array}{r}415 \cdot 71 \\
\pm 18 \cdot 20\end{array}$ & $\begin{array}{r}403 \cdot 79 \\
\pm 39 \cdot 91\end{array}$ & $\begin{array}{r}340.97 \\
\pm 39.91\end{array}$ \\
\hline$H_{1}$ & $\begin{array}{r}54.55 \\
\pm 8.64\end{array}$ & $\begin{array}{r}29 \cdot 12 \\
\pm 5 \cdot 14\end{array}$ & $\begin{array}{r}19 \cdot 27 \\
\pm 5 \cdot 61\end{array}$ & $\begin{array}{r}22 \cdot 10 \\
\pm 4.53\end{array}$ & $\begin{array}{r}54.99 \\
\pm 10.69\end{array}$ & $\begin{array}{r}165 \cdot 27 \\
\pm 38.73\end{array}$ & $\begin{array}{r}386 \cdot 28 \\
\pm 84.93\end{array}$ & $\begin{array}{r}466 \cdot 59 \\
\pm 84 \cdot 91\end{array}$ \\
\hline$H_{2}$ & $\begin{array}{r}21 \cdot 43 \\
\pm 7 \cdot 34\end{array}$ & $\begin{array}{r}25 \cdot 83 \\
\pm 4 \cdot 37\end{array}$ & $\begin{array}{r}33 \cdot 26 \\
\pm 4 \cdot 77\end{array}$ & $\begin{array}{r}14.59 \\
\pm 3.85\end{array}$ & $\begin{array}{r}28 \cdot 18 \\
\pm 9 \cdot 09\end{array}$ & $\begin{array}{r}66 \cdot 29 \\
\pm 32.93\end{array}$ & $\begin{array}{r}182 \cdot 32 \\
\pm 72 \cdot 21\end{array}$ & $\begin{array}{r}158 \cdot 74 \\
\pm 72 \cdot 19\end{array}$ \\
\hline$h^{2}$ & $\begin{array}{r}2 \cdot 67 \\
\pm 4 \cdot 91\end{array}$ & $\begin{array}{r}5 \cdot 00 \\
\pm 2 \cdot 92\end{array}$ & $\begin{array}{r}6 \cdot 34 \\
\pm 3 \cdot 19\end{array}$ & $\begin{array}{r}8 \cdot 42 \\
\pm 2 \cdot 58\end{array}$ & $\begin{array}{r}42 \cdot 28 \\
\pm 6 \cdot 08\end{array}$ & $\begin{array}{r}190 \cdot 63 \\
\pm 22 \cdot 02\end{array}$ & $\begin{array}{r}112.29 \\
\pm 48.29\end{array}$ & $\begin{aligned} & 0.984 \\
\pm & 48 \cdot 28\end{aligned}$ \\
\hline$F$ & $\begin{array}{r}49 \cdot 65 \\
\pm 9 \cdot 37\end{array}$ & $\begin{array}{l}-3 \cdot 74 \\
\pm 5 \cdot 57\end{array}$ & $\begin{array}{l}-7 \cdot 90 \\
\pm 6 \cdot 09\end{array}$ & $\begin{array}{r}6.71 \\
\pm 4.92\end{array}$ & $\begin{array}{r}44.59 \\
\pm 11.60\end{array}$ & $\begin{array}{r}294 \cdot 88 \\
\pm 42 \cdot 01\end{array}$ & $\begin{array}{r}380 \cdot 04 \\
\pm 92 \cdot 13\end{array}$ & $\begin{array}{r}248 \cdot 36 \\
\pm 92 \cdot 11\end{array}$ \\
\hline$E$ & $\begin{array}{r}1.91 \\
\pm 1.22\end{array}$ & $\begin{array}{r}2.24 \\
\pm 0.73\end{array}$ & $\begin{array}{r}5 \cdot 57 \\
\pm 0.79\end{array}$ & $\begin{array}{r}0.87 \\
\pm 0.64\end{array}$ & $\begin{array}{r}3.55 \\
\pm 1.51\end{array}$ & $\begin{array}{r}49 \cdot 13 \\
\pm 5 \cdot 49\end{array}$ & $\begin{array}{r}10 \cdot 49 \\
\pm 12 \cdot 03\end{array}$ & $\begin{array}{r}14 \cdot 01 \\
\pm 12 \cdot 03\end{array}$ \\
\hline $\begin{array}{l}\text { Degree of } \\
\text { dominance }\end{array}$ & $1 \cdot 05$ & $1 \cdot 08$ & $0 \cdot 57$ & $0 \cdot 85$ & $0 \cdot 78$ & $0 \cdot 63$ & $0 \cdot 97$ & $1 \cdot 16$ \\
\hline$H_{2} / 4 H_{1}$ & $0 \cdot 098$ & $0 \cdot 222$ & $0 \cdot 43 \mathrm{I}$ & $0 \cdot 165$ & $0 \cdot 130$ & $0 \cdot 10$ & $0 \cdot 118$ & $0 \cdot 085$ \\
\hline$\frac{\left(4 D H_{1}\right) \frac{1}{2}+F}{\left(4 D H_{1}\right) \frac{1}{2}-F}$ & $2 \cdot 83$ & $0 \cdot 870$ & 0.790 & $1 \cdot 29$ & $1 \cdot 92$ & $3 \cdot 57$ & $2 \cdot 85$ & 1.90 \\
\hline$h^{2} / H_{2}$ & $0 \cdot 124$ & $0 \cdot 194$ & $0 \cdot 191$ & $0 \cdot 577$ & $1 \cdot 50$ & $2 \cdot 87$ & $0 \cdot 616$ & 0.006 \\
\hline$r(\bar{x}$ and $W r+V r)$ & $-0 \cdot 42$ & $0 \cdot 05$ & $0 \cdot 15$ & $0 \cdot 19$ & 0.87 & $0 \cdot 37$ & $0 \cdot 73$ & -0.77 \\
\hline Heritability* & $79 \cdot 7$ & $37 \cdot 3$ & $54 \cdot 4$ & $61 \cdot 4$ & $78 \cdot 6$ & $86 \cdot 1$ & $89 \cdot 3$ & $55 \cdot 4$ \\
\hline
\end{tabular}

position of points having the greatest proportion of recessive genes. Most of the late parents occupied intermediate positions and in general Otis (No. 7), Line 7-2 (No. 3) and C.I. 1236 (No. 8) which were intermediate in rate of earing, occupied positions near to the origin which indicated that they contained a high proportion of dominant genes controlling rate of ear emergence.

\section{(d) Genetic components and their interaction with environment}

Estimates of the genetic components of variation, degree of dominance and heritability for ear emergence in the eight different environments are given in table 6 . Highly significant estimates of $D$ and $H_{1}$ were obtained in all the environments which indicates that both additive and dominance components were responsible for the expression of ear emergence in this material. This confirms the conclusion obtained from the analysis of variance of diallel tables (table 5). The degree of dominance ranged from 
partial dominance in five environments to slight overdominance in three environments. This test confirms that the rate of ear emergence, although showing additivity, was also strongly influenced by dominance in certain environments. The ratio $H_{2} / 4 H_{1}$ indicated asymmetry of genes with positive and negative effects at loci showing dominance. Theoretically this rate should not exceed 0.25 , thus the value of 0.431 obtained in environment III must be considered spurious. In most environments the ratio $\left(4 D H_{1}\right)^{\frac{1}{2}}$ $+F /\left(4 D H_{1}\right)^{\frac{1}{2}}-F$ indicated that the proportion of dominant and recessive allelomorphs in the parents was unequal and that for each recessive gene governing this character there were at least two or even more (e.g. in controlled environment VI) dominant genes or gene groups. The ratio $h^{2} / H_{2}$, which provides an estimate of the number of effective factors which exhibit dominance, ranged from 0 in VIII to nearly 3 in environment VI. This indicated that of the genes which control this character, at least one gene or

TABLE 7

Analysis of variance for $\mathrm{Wr}+\mathrm{Vr}$ for the ten arrays in the eight environments

\begin{tabular}{lrc}
\multicolumn{1}{c}{ Source } & d.f. & M.S. \\
Environments & 7 & $230371 \cdot 0 * *$ \\
Arrays & 9 & $24855 \cdot 8$ \\
Arrays $\times$ Environments & 63 & $14902 \cdot 7 * *$ \\
Error & 80 & $592 \cdot 1$ \\
& $* * \mathrm{P}<0 \cdot 01$.
\end{tabular}

gene group exhibited dominance to some degree. However, this value contrasts with the indications from estimates of the degree of dominance and the estimates of frequency of dominant recessive genes, but the estimate obtained from $h^{2} / H_{2}$ assumes equality and absence of opposition in dominance of the various gene loci which is not likely to apply in this material in view of the estimates for $H_{2} / 4 H_{1}$. In normal environments the poor association between the parental order of dominance and the parental measurements showed that neither late nor early parents contained all dominant genes, but rather that parents with intermediate flowering contained the highest proportion of dominant genes. This is also reflected in the position of arrays in the $W r / V r$ graphs. However, a direct contradiction in $r$ values (ranging from +0.73 in environment VII to -0.77 in environment VIII) shows that the genetic systems controlling ear emergence exhibit different expressions of dominance in the different environments.

Estimates of heritability, in the narrow sense, were high in most environments. However, the range in values from 37 per cent. to 89 per cent. emphasises their limited usefulness when estimates obtained in one environment are translated to another environment, even when using the same material and recording the same character. In order to obtain some indication of the variation in the dominance components in different environmental conditions, an analysis of variance of $\mathrm{Wr}+\mathrm{Vr}$ values was carried out using data from all environments (table 7). The differences between arrays were not significant when tested against their interaction with the environment, although they were significant when tested against the error term. The significant arrays $\times$ environment interaction indicates that the relative dominance of the parents varied considerably with the environments. 
To study more precisely the interaction of the additive and dominance components with the environments, regression coefficients of these components on the environmental means were calculated and tested for significance (table 8$)$. The $b$ value for the additive component $(b=4.62 \pm 1 \cdot 72)$ was significant $(\mathrm{P}<0.05)$, however, the $b$ value for dominance was not significantly different from zero $(b=2 \cdot 53 \pm 2 \cdot 34)$; neither was the difference between the two regression slopes significant (table $8 a$ ). The regression analysis (table $8 b$ ) confirmed that a significant portion of the additive $x$ environment interactions was accounted for by the linear function of the

TABLE 8

Analysis of response of additive (D) and dominance $\left(\mathrm{H}_{1}\right)$ components of genetic variation to changes over eight environments

(a) Regression and correlation coefficients between components of genetic variation and the environment means

\begin{tabular}{|c|c|c|c|c|c|c|c|}
\hline \multirow[b]{2}{*}{$X$} & \multirow[b]{2}{*}{$r$} & \multirow[b]{2}{*}{$b$} & \multicolumn{2}{|c|}{$b=0$} & \multicolumn{2}{|c|}{$b_{1}-b_{2}$} & \multirow[b]{2}{*}{$r$} \\
\hline & & & $t_{6}$ & $P$ & $t_{12}$ & $P$ & \\
\hline $\begin{array}{l}\text { Environment } \\
\text { means }\end{array}$ & $\begin{array}{l}\text { Additive } \\
(D)\end{array}$ & $4 \cdot 62 \pm 1 \cdot 72$ & $2 \cdot 48$ & $5 \%$ & & & 0.68 \\
\hline $\begin{array}{l}\text { Environment } \\
\text { means }\end{array}$ & $\begin{array}{c}\text { Dominance } \\
\left(H_{1}\right)\end{array}$ & $2 \cdot 53 \pm 2 \cdot 34$ & 1.08 & N.S. & & & 0.40 \\
\hline
\end{tabular}

(b) Regression analysis

Mean squares for components of genetic variation

Item

Regression

Remainder

Error

$\begin{array}{cc}\text { Additive }(D) & \text { Dominance }\left(H_{1}\right) \\ 120078 \cdot 7^{* *} & 36080 \cdot 0^{*} \\ 19212 \cdot 0^{*} & 31079 \cdot 1^{*} \\ 10 \cdot 96 & 10 \cdot 96\end{array}$

** Significant regression M.S. against both the error M.S. $(P<0 \cdot 01)$ and its remainder M.S. $(P<0 \cdot 05)$. M.S.

* Significant regression M.S. and remainder M.S.'s $(P<0 \cdot 01)$, when tested against error

environment means. However, both the additive and dominance components showed deviations around their regression slopes, and the variation for the latter was far higher (fig. 3) than for the additive component, which indicates that the relationship between the environmental means and the expression of both additive and dominance components is not simple and straightforward.

\section{Discussion}

Plant breeders are well aware of the problems posed by genotypeenvironment interactions in breeding better varieties, but until recently, there was no agreement about the analytical approaches which could be used to provide reliable estimates of genotype-environment interactions. Two main approaches, one purely statistical (Yates and Cochran, 1938; Finlay and Wilkinson, 1963; Eberhart and Russell, 1966) and the other based on biometrical genetics (Mather and Jones, 1958; Jinks and Stevens, 1959; Bucio Alanis, 1966; Bucio Alanis and Hill, 1966; Perkins and Jinks, 1968a, 
$b$; Bucio Alanis et al., 1969) are now available. Both types of analyses have yielded similar results in showing that the genotype-environment interaction component is often a linear function of the environmental means. In the present work a major portion of these interactions both in the parental and $\mathrm{F}_{1}$ generations was accounted for by the linear function of the environmental values although a significant portion was independent of this linear component.

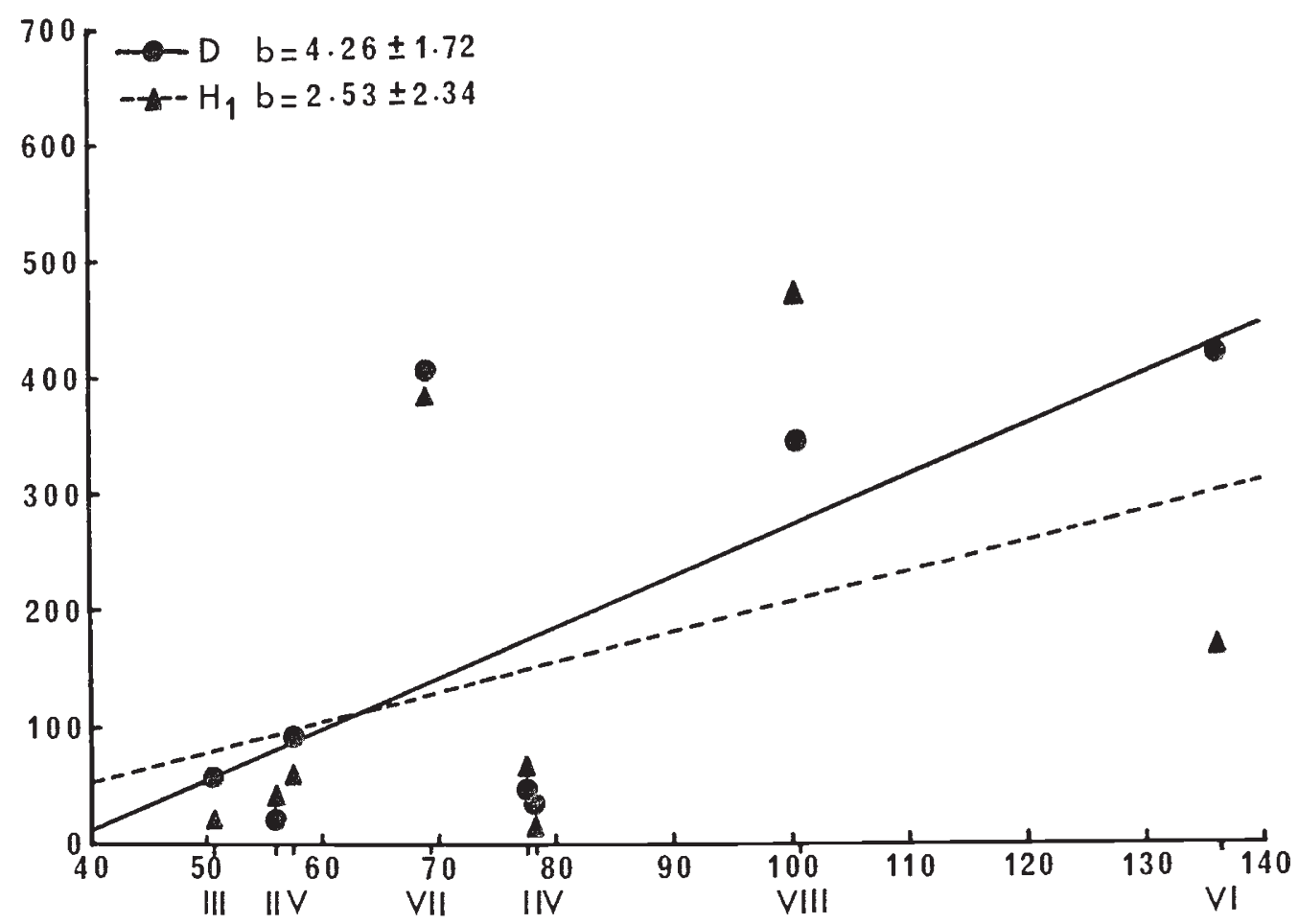

Environment means

FIG. 3.-Regressions of the additive and dominance components on environmental means.

Eberhart and Russell (1966) defined both the linear and non-linear function of the genotype-environment interactions as "stability parameters" $\beta_{i}$ (linear regression) and $\bar{S}_{d}^{2}$ (deviation from the regression) respectively. They emphasised that the phenotypic expression $(Y)$ of a particular genotype $(i)$ in a specific environment $(j)$ depends on the mean expression $\left(\mu_{i}\right)$, the linearity of response of that genotype to changes in the environment $\left(\beta_{i}\right)$ and the extent of residual deviations from the regression $\left(\delta_{i j}\right)$. Perkins and Jinks (1968b) observed that these two components of the genotype-environmental interaction are independent and presumably subject to the control of different genetic systems. In our material, the presence of significant $\beta_{(i l)}$ values for only those $F_{1}$ 's which involved either one or both the parents having $\beta_{i}$ values greater than unity, confirms that the linear response is under genetic control and subject to dominance (see tables 2 and 4). Similarly, the generally low estimates of $\bar{S}_{d}^{2}$ in array 3 (involving line 7-2) indicate genetic control and dominance for the non-linear component in this material. 
Thus these results confirm the findings of Perkins and Jinks (1968b) that both these components are under the control of different gene systems.

The weak correlation between magnitude of the linear regressions and the mean performance of the varieties did not persist into the $\mathrm{F}_{1}$ generation. Thus, no predictions about the linear response in different environments of either the parents of $\mathrm{F}_{1}$ 's would be possible on the basis of their mean performance (see Jinks and Mather, 1955; Perkins and Jinks, 1968a, b). It was noticeable in this material that the range of the "linear" and "non-linear" components of the genotype-environment interactions was greater in the parents than in the $\mathrm{F}_{1}$ 's. It is possible that the high variation for the nonlinear component $\left(S_{b}\right)$ among the parents could be accounted for by the wide genetic diversity (see Perkins and Jinks, 1968b) of the material consciously included in this investigation.

Genotype-environment interactions can result in considerable upward bias in estimates of genetic components. In considering this aspect, Gardner (1963) emphasised the need to determine the relative magnitude of the variances due to the interactions of additive and dominance gene effects with the environment before it is possible to decide which component of genetic variation could be exploited in a breeding programme. Previous investigations have shown that both the additive and dominance components can interact with changes in the environment (Rojas and Sprague, 1952; Matzinger et al., 1959; Liang, 1967; Paroda and Joshi, 1970).

A number of workers including Jinks and Mather (1955), Jinks and Stevens (1959), Bucio Alanis and Hill (1966), Bucio Alanis, Perkins and Jinks (1969), Jinks and Perkins (1969) and Breese (1969) have investigated the relative sensitivity of additive, dominance and epistatic components and they have found situations in which the dominance component has been more sensitive, equally sensitive and less sensitive than the additive component. This investigation confirms that both the additive and dominance components interact with the environment. Although a major portion of the additive-environment interaction was accounted for by a linear relationship, a large portion of both the additive-environment interaction and dominance-environment interaction was non-linear. However, there is no theoretical reason to expect a simple linear relationship between the additive component and the environmental means to hold. Further, as far as the dominance component is concerned, an even more complex situation than for additivity may be expected to occur (Perkins and Jinks, personal communication). Further information on these relationships is therefore needed before any generalisation about the stability of the genetic components is possible.

Originally Finlay and Wilkinson used the term "stability" to refer to the slope of the regression lines, genotypes with the most gentle slopes being referred to as the most stable in contrast to genotypes having the steepest slopes, which were the least stable. In view of the recent developments in analytical approaches, it is preferable now to consider the linear regression lines as measures of the relative response of genotypes to changes in the environment. Thus genotypes which take relatively the same amount of time to reach ear emergence over a wide range of environments would have $b$ values less than unity and would be least responsive to changes in the environment. Thus, in this investigation the induced mutant M-12a (No. 9) with $b=0.619$ would be the least, and Proctor No. $2(b=1.467)$ 
the most responsive parent varieties. In the absence of a more appropriate term, it is preferable to use "stability" to refer to the measurements of unpredictable variation in response to changes in the environment as indicated by deviations from the linear regression lines (see Breese, 1969). This latter definition of the term "stability" would then be the same as Eberhart and Russell's second parameter of stability $\left(\bar{S}_{d}^{2}\right)$, and is used in this paper. A measure of this attribute of a genotype can be obtained from either the $\bar{S}_{d}^{2}$ or the standard errors $\left(S_{b}\right)$ attached to each regression line, thus the genotype with the smallest amount of variability around the regression line is considered to be the most stable. In this context Line 21-2 (No. 4) within this sample of parents, would be considered the least and $\mathrm{Cb} 883$ (No. 6) the most stable as far as ear emergence is concerned. In selecting genotypes likely to give a predicted rate of earing in a given environment, both the mean value for rate of ear emergence and the regression slopes of the varieties concerned would also have to be considered. Selection for an early flowering and stable genotype in a range of environments would require a low mean, the least possible regression slope $(b=0$ to $<\mathrm{I} \cdot 0)$ and the least deviation around the slope. On the other hand, a breeder interested in obtaining relatively late flowering and stable genotypes over a wide range of environments might consider selecting lines having a high mean, a regression slope around $\mathrm{I} \cdot 0$, and the least deviation around the regression line.

Regarding the genetic system controlling the rate of ear emergence in spring barley these results confirm the previous observations that this character is quantitatively inherited and that it is partially governed by dominant genes or gene groups (Johnston, 1934; Johnston and Aamodt, 1935; Smith, 1951; Takahashi and Yasuda, 1956; Eunus, 1964). In the varieties under investigation both additive and dominance components were responsible for the expression of this character. The considerable shift in the position of relative dominance of different arrays from normal to controlled environments emphasise the need to carry out genetic studies in environments closely allied to those in which the information is going to be applied.

As regards the performance of particular genotypes, the induced mutant M-12a (No. 9) from the variety Bonus provides a good source of earliness, and in this investigation was earlier than any other genotype over a wide range of environments. Line 7-2 (No. 3), while it was more stable than No. 9 was only as early as No. 9 in the early environments; in the later environments it was responsive to the changed environment and eared considerably later than M-12a. Cb 883 (No. 6) can be used as a medium flowering, stable genotype in different environments. As far as $\mathrm{F}_{1}$ hybrids are concerned in view of the existing dominance pattern, exploitation of Line 7-2 (No. 3) would help in obtaining the most stable and superior hybrids. No doubt considerable efforts would be required by a breeder in the selection of such parents from the available genetic stock, but the premium in hybrid production is bound to be great. The $\mathrm{F}_{1}$ hybrids between Line 7-2 (No. 3) $\times$ Cb 824 (No. 5), Line 7-2 (No. 3) x Otis (No. 7) and Line 7-2 (No. 3) $\times$ M-12a (No. 9) could confidently be predicted to be the most stable early hybrids, while Proctor (No. 2) × Cb 883 (No. 6) would probably yield the most stable late $\mathrm{F}_{1}$ hybrid.

The analysis, as carried out in this paper, illustrates the power of the analytical techniques now becoming available for the use of the breeder. 
Because data from a range of environments can be considered as a single unit, a pattern of genotype-environment interactions is becoming apparent, which will greatly simplify the task of the breeder in developing either specific or generally adapted genotypes. As discussed earlier, such studies would also be of immense help in selecting the most stable and superior hybrids and would thus aid considerably in the $\mathrm{F}_{1}$ hybrid breeding programmes.

\section{Summary}

An investigation of genotype-environment interactions for ear emergence in ten spring barley genotypes grown in eight different environments shows that:

1. Genotype-environment interactions were operative in both the parental and $\mathrm{F}_{1}$ generations and that a significant portion of these interactions was accounted for by the linear function of the environmental means. Some of the interaction was, however, independent of this linear component.

2. Both the linear and non-linear components of the genotype-environment interactions were under the control of different gene systems. In the material analysed, two different parents, Proctor and Line 7-2, showed dominance for the linear and for the non-linear components, respectively.

3. Interaction between the additive component and the environment was greater than that of the dominance component in the different environments.

4. Rate of ear emergence in this material was governed by partial dominance.

5. The irradiated mutant M-12a from Bonus exhibited the most rapid rate of ear emergence in all environments. The recessive earliness of this genotype could provide a good source of new genetic variation for improved earliness in barley.

6. The practical implications of the study of genotype-environment interactions for practical plant breeding are discussed briefly.

Acknowledgments.-We wish to thank Professors P. T. Thomas, C.B.E., and H. Rees for their encouragement and Professor J. L. Jinks, Dr Jean M. Perkins, Dr E. L. Breese and Dr J. Hill for reading the manuscript and offering suggestions, and D. L. Jones and Mrs D. Ralphs for technical assistance. One of us (R. S. P.) wishes to thank the Commonwealth Scholarship Commission in the United Kingdom for a post-doctorate fellowship award.

\section{References}

BREESE, E. L. 1969. The measurement and significance of genotype-environment interactions in grasses. Heredity, 24, 27-44.

BUCIO-AlANis, L. 1966. Environmental and genotype-environmental components of variability. I. Inbred lines. Heredity, 21, 387-397.

BUCiO-AlANIs, L., AND HILL, J. I966. Environmental and genotype-environmental components of variability. II. Heterozygotes. Heredity, 21, 399-405.

BUCIO-AlANIS, L., PERKINS, JEAN M., AND JINKs, J. L. I969. Environmental and genotypeenvironmental components of variability. V. Segregating generations. Heredity, 24, 115-127.

EBERHART, S. A., AND RUSSELl, W. A. 1966. Stability parameters for comparing varieties. Crop Sci., 6, 36-40.

EUNUS, A. M. 1964. Inheritance of earliness in barley. Euphytica, 13, 49-56.

FINLAY, K. W., AND WILKINson, G. N. 1963. The analysis of adaptation in a plant breeding programme. Aust. F. Agric, Res., 14, 742-754. 
GARDNER, C. O. 1963. Estimates of genetic parameters in cross-fertilizing plants and their implications in plant breeding. Symposium on Statistical Genetics and Plant Breeding. NAS NRG Pub. 982, 225-252.

HAYMAN, B. I. 1954a. The analysis of variance of diallel tables. Biometrics, 10, 235-244. HAYMAN, B. I. 1954b. The theory and analysis of diallel crosses. Genetics, 39, 789-809. JINks, J. L. 1954. The analysis of continuous variation in a diallel cross of Micotiana rustica varieties. Genetics, 39, 767-788.

Jinks, J. L., AND hayman, B. I. 1953. The analysis of diallel crosses. Maize Genetics News Letter, 27, 48-54.

JINKs, J. L., AND MATHER, K. 1955. Stability in development of heterozygotes and homozygotes. Proc. Roy. Soc. B., 143, 561-578.

JINKS, J. L., AND STEVENS, J. M. 1959. The components of variation among family means in diallel crosses. Genetics, 44, 297-308.

JINKS, J. L., AND PERKINS, JEAN M. 1969. The detection of linked epistatic genes for a metrical trait. Heredity, 24, 465-475.

JOHNStON, w. H. 1934. Studies on the dehulling of barley kernels with sulphuric acid and on the inheritance of reaction to covered smut, Ustilago hordei (PERS.) K. \& S. Infection in crosses between Glabron and Trebi barleys. Can. 7. Research C., 11, 458-473.

JOHNSTON, w. H., AND AADMODT, o. s. 1935. Breeding of disease resistant smooth-awned varieties of barley. Can. F. Research C., 13, 315-338.

LIANG, G. H. 1967. Diallel analysis of agronomic characters in grain sorghum, Sorghum vulgare Pers. Can. 7. Genet. Cytol., 9, 269-276.

MATHER, K., AND JONES, R. MORLEY. 1958. Interaction of environment in continuous variation. I. Description. Biometrics, 14, 343-359.

MATZINGER, D. F., SPRAGUE, G. F., AND COCKERHAM, C. C. 1959. Diallel crosses of maize in experiments repeated over locations and years. Agron. F., 51, 346-350.

PARODA, R. S., AND JOSHI, A. B. 1970. Genetic architecture of yield and components of yield in wheat (Triticum aestivum L.). Indian 7. Genet. Pl. Breed. (in press).

PERKINS, JEAN M., AND JINKS, J. L. 1968a. Environmental and genotype-environmental components of variability. III. Multiple lines and crosses. Heredity, 23, 339-356.

PERKINS, JEAN M., AND JINKS, J. L. $1968 b$. Environmental and genotype-environmental components of variability. IV. Non-linear interactions for multiple inbred lines. Heredity, 23, 525-535.

ROJAS, B. A., AND SPRAGUE, G. F. 1952. A comparison of variance components in corn yield trials. III. General and specific combining ability and their interactions with locations and years. Agron. 7., 44, 462-466.

SMITH, L. 1951. Cytology and genetics of barley. Bot. Rev., 17, 133-335.

TAKAHASHI, R., AND yasuda, s. 1956. Genetic studies of time of heading in barley. Proceed. Internl. Genetics Symposia, Supl. Vol. Cytologia (1957), 489-501.

yATES, F., AND COCHRAN, w. G. 1938. The analysis of groups of experiments. 7 . of Agric. Sci., 28, 556-580. 